\section{Genetics of autism}

\section{Genética do autismo}

Dear Editor,

We have read with special interest the paper "Genetics of Autism" by Carvalheira et $\mathrm{al}^{1}$ and we would like to contribute for this important updating work by presenting and discussing some interesting data in this area.

Genome-wide screens have also found two interesting genetic sites of putative autism susceptibility on chromosomes 3p25p26 and 6 q21 with linkage scores higher than 2.0 (highest LOD scores: $3 p 25-p 26$ was $2.88,{ }^{2}$ and $6 q 21$ was $2.23^{3}$ ). These chromosomal regions also contain candidate genes for autism that belong to cerebral systems supposedly related to the disorder. The chromosome 3p25-p26 contains the oxytocin (OT) receptor gene, ${ }^{4}$ and the chromosome $6 q 21$ contains the human glutamate receptor- 6 kainate-preferring receptor (GluR6) gene. ${ }^{5}$

OT system has been involved in the sociability abnormalities presented in autism. Animal studies have shown that OT levels affect social behavior in mice. Children with autism present low plasma OT levels, and the ratio of the inactive OT precursor (OT-X) to active OT peptide seems to be significantly higher in children with autism. ${ }^{6}$

The glutamate system may play an important role in the pathophysiology of autism. The GluR6 gene on chromosome $6 q 21$ was associated with autism by linkage disequilibrium and multipoint linkage analysis, and a surveyed autistic population possessed a single amino acid substitution in GluR6 (M867I) in a highly conserved domain of the intracytoplasmic C-terminal region of the protein (this change was found in $8 \%$ of autistic subjects and in $4 \%$ of controls). ${ }^{7}$ Some studies have implicated the marker $155 \mathrm{CA}-2$ in the gammaaminobutyric acid (GABA) type-A receptor beta3 subunit gene (GABRB3), and the metabotropic glutamate receptor gene (GRM8) on chromosome 7q31-q33 in the susceptibility for autism. ${ }^{6}$ Although apparently contradictory, several evidence suggest the involvement of the glutamate system in the pathophysiology of autism. Symptoms of hypoglutamatergia (defective habituation, impaired attention, a meagre behavioral repertoire and a general behavioral primitivization) simulate the autistic behavior in rodent model study; serotonin receptor 2A (5HT2A) agonists cause behavior similar to autism, perhaps via expression of $5 \mathrm{HT} 2 \mathrm{~A}$ on glutamatergic-inhibiting GABAergic neurons (intimate interplay between central glutamate and serotonin, notably the serotonin (5-HT) $2 \mathrm{~A}$ receptor, has been shown by several investigations); an excessive glutamatergic activity is associated with epilepsy, which is highly common in autism (up to a third of patients with autism); the mRNA levels of the excitatory amino acid transporter 1 and glutamate receptor AMPA 1 genes, two members of the glutamate system, were significantly increased, showing an upregulated expression of them in postmortem studies of brain tissue of autistic patients. ${ }^{6}$

These data have shown the importance of chromosomes $3 p 25-p 26$ and $6 q 21$ for the investigation of the genetic susceptibility for autism.

Quirino Cordeiro, Homero Vallada Department of Psychiatry, Universidade de São Paulo (USP), São Paulo (SP), Brazil
Financing: None

Conflict of interests: None

\section{References}

1. Carvalheira G, Vergani N, Brunoni D. Genetics of autism. Rev Bras Psiquiatr. 2004;26(4):270-2

2. Auranen M, Vanhala R, Varilo T, Ayers K, Kempas E, Ylisaukko-Oja $\mathrm{T}$, et al. A genomewide screen for autism-spectrum disorders: evidence for a major susceptibility locus on chromosome 3q2527. Am J Hum Genet. 2002;71(4):777-90.

3. Philippe A, Martinez M, Guilloud-Bataille M, Gillberg C, Rastam M, Sponheim E, et al. Genome-wide scan for autism susceptibility genes. Paris Autism Research International Sibpair Study. Hum Mol Genet. 1999;8(5):805-12.

4. Online Mendelian Inheritance in Man: OMIM [database on the Internet]. Bethesda (MD):National Library of Medicine (US):2002 [cited 2005 may 12]. 167055 Oxytocin Receptor; OXTR: [about 2 p.]. Available from: http://www.ncbi.nlm.nih.gov/entrez/ dispomim.cgi?id $=167055$

5. Online Mendelian Inheritance in Man: OMIM [database on the Internet]. Bethesda (MD): National Library of Medicine (US):2002 [cited 2005 may 12]. 138244 Glutamate receptor, Ionotropic, Kainate 2; Grik2: [about 2 p.]. Available from: http:// w w w. n c b i. n I m. n i h. g o v/ e n t r e z/ dispomim.cgi?cmd =entry\&id $=138244$

6. Muhle R, Trentacoste SV, Rapin I. The genetics of autism. Pediatrics. 2004;113(5):e472-86.

7. Jamain S, Betancur C, Quach H, Philippe A, Fellous M, Giros B, Gillberg C, Leboyer M, Bourgeron T. Paris Autism Research International Sibpair (PARIS) Study. Linkage and association of the glutamate receptor 6 gene with autism. Mol Psychiatry. 2002;7(3):302-10.

\section{A memantina como terapia adjuvante para os sintomas negativos da esquizofrenia}

Memantine as an adjunctive therapy for

\section{schizophrenia negative symptoms}

\section{Sr. Editor,}

Os antipsicóticos atípicos trouxeram uma melhora marcante nos sintomas negativos da esquizofrenia. Entretanto, muitos pacientes permanecem refratários à remissão destes sintomas, fato que piora muito a qualidade de vida e a deterioração psicossocial destes indivíduos. Recentemente, a memantina, um antagonista dos receptores $\mathrm{N}$-metil D-aspartato (NMDA), foi descrita como uma substância neuroprotetora na esquizofrenia; ${ }^{1}$ um relato de caso mostrou a efetividade deste fármaco na esquizofrenia catatônica. ${ }^{2}$ A seguir, relatamos três casos clínicos sobre a melhora dos sintomas negativos com uso de memantina em pacientes do sexo feminino com diagnóstico de esquizofrenia pelo DSM-IV e uso de antipsicóticos atípicos, em atendimento ambulatorial. Os sintomas foram avaliados através da Escala Breve de Avaliação Psiquiátrica Versão Ancorada (BPRS-A) ${ }^{3}$ antes do uso da memantina (TO) e após quatro semanas (T4). Desconhecemos outros relatos semelhantes na literatura até o momento.

Paciente A, 56 anos, em uso de sulpirida $800 \mathrm{mg}$ por dia. Apresentava em T0, predominantemente, retraimento afetivo 
e embotamento afetivo, sendo que cada um deles pontuou 6 BPRS-A $;^{3}$ o escore total neste momento foi 46 . Foi mantida a sulpirida em $800 \mathrm{mg}$ diários e iniciada memantina 5 mg por dia com o incremento de $5 \mathrm{mg}$ a cada sete dias até atingir 20 $\mathrm{mg}$ por dia. Em T4, os escores para retraimento afetivo e embotamento afetivo diminuíram para 1 e 2 , respectivamente; o escore total foi 26.

Paciente B, 31 anos, usando risperidona $6 \mathrm{mg}$ por dia. Os sintomas predominantes apresentados em T0 eram desorganização conceitual, que pontuou 5, retraimento afetivo e embotamento afetivo, cada um deles pontuou 6; o escore total neste momento foi 44 . A risperidona foi mantida em $6 \mathrm{mg}$ diários e a memantina foi iniciada com $5 \mathrm{mg}$ por dia; houve um incremento semanal de $5 \mathrm{mg}$ até $20 \mathrm{mg}$ por dia. Em T4, os escores para retraimento afetivo e embotamento afetivo diminuíram para 4 cada um e a desorganização conceitual permaneceu pontuando 5; o escore total foi 39 .

Paciente C, 20 anos, em tratamento com clozapina $700 \mathrm{mg}$ por dia. Apresentava em TO, de forma mais acentuada, pensamentos não habituais, que pontuou 6 , retraimento afetivo e embotamento afetivo, que pontuaram 4 e 6 , respectivamente; o escore total neste momento foi 42. A clozapina foi mantida em 700 mg por dia e iniciada memantina 5 mg por dia com o incremento semanal de $5 \mathrm{mg}$ até $20 \mathrm{mg}$ diários. Em T4, os escores para retraimento afetivo e embotamento afetivo diminuíram para 1 e 2 , respectivamente. A desorganização conceitual permaneceu pontuando 5; o escore total foi 26.

Estados hiperglutamatérgicos têm sido implicados na fisiopatologia da esquizofrenia. ${ }^{4} \mathrm{O}$ excesso de glutamato causa excitação nos receptores NMDA, que são uma classe de receptores glutamatérgicos, permitindo um fluxo de cálcio para dentro da célula nervosa por longos períodos. Este influxo excessivo causa peroxidação lipídica nos neurônios, podendo progredir para morte neuronal. Os esquizofrênicos apresentam maior peroxidação lipídica ${ }^{5}$ do que indivíduos sem esquizofrenia. A memantina, por sua ação antagonista dos receptores NMDA e com base nos resultados destes três relatos clínicos, pode ser útil como terapia adjuvante no tratamento da esquizofrenia, principalmente dos sintomas negativos.

Clarissa Severino Gama, Paula Antunes, Carolina Moser, Paulo Silva Belmonte-de-Abreu Serviço de Psiquiatria, Hospital de Clínicas de Porto Alegre, Porto Alegre (RS), Brasil

Financing: None

Conflict of interests: None

\section{Referências}

1. Rands GS. Memantine as a neuroprotective treatment in schizophrenia. Br J Psychiatry. 2005;186:77; author reply 77-8.

2. Thomas C, Carroll BT, Maley RT, Jayanti K, Koduri A. Memantine and catatonic schizophrenia. Am J Psychiatry. 2005;162(3):626.

3. Romano F, Elkis H. Tradução e adaptação de um instrumento de avaliação psicopatológica das psicoses: a escala breve de avaliação psiquiátrica versão ancorada (BPRS-A). J Bras Psiquiatr. 1996;45(1):43-9.

4. Bressan RA, Pilowsky LS. The glutamatergic hypothesis of schizophrenia. Rev Bras Psiquiatr. 2003;25(3):177-83.

5. Gama CS, Salvador M, Andreazza AC, Kapczinski F, Belmonte-deAbreu PS. Níveis séricos elevados de superóxido dismutase e dos produtos de reação com o ácido tiobarbitúrico em pacientes esquizofrênicos cronicamente medicados. Rev Bras Psiquiatr. 2004;26 Supl 2:92. 